\title{
CORTES JUDICIALES, GOBERNADORES Y LEGISLADORES EN LAS PROVINCIAS ARGENTINAS: PATRONES DE CAMBIO DE JUECES (1983-2011)*
}

\author{
Judicial Courts, Governors and Legislators in the Argentine Provinces: \\ Patterns of Change in Judges (1983-2011)
}

\author{
AUGUSTO ABDULHADI \\ Universidad Nacional de General San Martín (UNSAM), Argentina
}

\begin{abstract}
RESUMEN
La literatura de estudios judiciales comparados sostiene que en Argentina los jueces de las Cortes cambian con frecuencia, y que son inducidos a retirarse a través de estrategias y presiones informales. Este trabajo argumenta que los cambios políticos de jueces de las Cortes se explican por mecanismos de negociación y cooptación, que están detrás de las estrategias informales utilizadas por los gobernadores. El supuesto principal es que los jueces dejan sus cargos cuando no tienen el respaldo político de líderes o facciones partidarios que puedan sostenerlos en el puesto, más allá de las presiones del gobernador de turno para removerlos. Para poner a prueba el argumento se realiza una tabla de verdad a partir de diez provincias argentinas.
\end{abstract}

Palabras clave: cortes judiciales, democracia, facciones, política subnacional, Argentina.

\begin{abstract}
The literature of comparative judicial studies maintains that in Argentina judges of the courts change frequently, and that they are induced to retire through informal strategies and pressures. This paper argues that the political changes of court judges are explained by mechanisms of negotiation and co-optation, which are behind the informal strategies used by governors. The main assumption is that judges leave their posts when they do not have the political backing of leaders or party factions that can sustain them in office, beyond the pressure of the governor in office to remove them. To test the argument, a truth table is made up of ten Argentine provinces.
\end{abstract}

Keywords: judicial courts, democracy, factions, sub-national politics, Argentina.

Este artículo es resultado de mi tesis para el Doctorado en Ciencia Política de la Universidad Nacional de General San Martín, Buenos Aires, Argentina. Se financió parcialmente con fondos del subsidio PICT 1712- 2014, “Democracia, estado y relaciones estado-sociedad en las provincias argentinas", de la Agencia Nacional de Promoción Científica y Tecnológica. Agradezco los comentarios de las dos revisiones anónimas de la revista sobre la versión previa de este documento, que permitieron mejorarlo. 


\section{INTRODUCCIÓN}

En 1992 el gobernador del partido Acción Chaqueña (PACH), Rolando Tauguinas, logró designar como juez del Superior Tribunal de Justicia de Chaco a un funcionario de su confianza, gracias al apoyo del peronismo. Así, tres de los cinco jueces del Superior Tribunal chaqueño provenían del peronismo (PJ), una jueza del radicalismo (UCR) y un juez de PACH. Un año después, el gobernador quiso deshacerse de los tres jueces peronistas que integraban el Superior Tribunal de Justicia. Promovió un juicio político contra esos tres jueces con apoyo de la UCR en la legislatura. Los diputados peronistas respaldaron a los jueces y bloquearon el intento. Desestimado el juicio político, uno de los jueces atacados renunció y el peronismo, con mayoría en el Consejo de la Magistratura, impuso como juez de la Corte chaqueña a un diputado provincial propio.

El gobernador quería que se eligiera a otra persona (Diario Norte, 30/4/1993), pero no pudo evitar que el peronismo mantuviera en ese momento su mayoría en la Corte provincial con tres de los cinco integrantes. Pocos años después, el gobernador radical Ángel Rozas pudo imponer como jueces del Superior Tribunal de Justicia a funcionarios de su gabinete y logró modificar la composición de la Corte chaqueña a su favor ¿Cómo se explican los cambios de jueces de las Cortes judiciales en diferentes contextos políticos, con y sin mayoría legislativa? ¿Por qué en algunas ocasiones los jueces del Superior Tribunal de Justicia (STJ) ${ }^{1}$ abandonan sus cargos ante presiones del gobernador y en otros casos resisten las amenazas?

La literatura de estudios judiciales comparados sostiene que, en Argentina, y América latina en general, existe una rotación frecuente de jueces de las Cortes y que los incentivos partidarios son un gran predictor de esos cambios (Pérez Liñán y Castagnola 2009; Lara Borges, Castagnola y Pérez Liñán 2012). Además, los jueces son inducidos a retirarse a través de estrategias y presiones informales (Castagnola 2010a, 2012), pero a nivel provincial en Argentina no existe una relación clara entre estos cambios y el porcentaje de bancas legislativas de que disponen los gobernadores (Castagnola 2010a, 2012; Leiras, Giraudy y Tuñón 2015).

Este trabajo argumenta que los cambios políticos de jueces de las Cortes se explican por mecanismos de negociación y cooptación que están detrás de las estrategias informales utilizadas por los gobernadores. La hipótesis es que los jueces dejan sus cargos en los STJ cuando no tienen respaldo político de líderes de partidos o facciones partidarias que puedan sostenerlos en el puesto, más allá de las presiones del gobernador de turno para removerlos.

Los mecanismos de negociación y cooptación parten de una situación de gobierno minoritario. El partido del gobernador no dispone de la mayoría nece-

La expresión "Superiores Tribunales de Justicia" (STJ) hace referencia a la máxima autoridad judicial en cada provincia, y la utilizo como sinónimo de "Cortes provinciales". 
saria para designar jueces de la Corte, o para removerlos, y entonces necesita reunir votos de otros partidos o facciones partidarias. Se sostiene que hay negociación cuando se trata de un acuerdo con otros partidos o facciones partidarias (sea un acuerdo entre diferentes partidos, o entre facciones partidarias de diferentes partidos). La principal diferencia del mecanismo de cooptación es que el partido del gobernador reúne un porcentaje de bancas legislativas muy cercano a la mayoría necesaria, y puede cooptar el voto de uno o unos pocos legisladores individuales para alcanzar la mayoría necesaria. Los distintos mecanismos se explican con más detalle en la primera sección de este trabajo.

Para poner a prueba el argumento se realizó una tabla de verdad (Ragin 2007) con diez provincias argentinas para las cuales se pudo reunir información completa del listado exhaustivo de jueces que integraron los STJ provinciales en el período estudiado (1983-2011) y la distribución de bancas legislativas en el mismo período. Las provincias incluidas son Chaco, Chubut, Ciudad Autónoma de Buenos Aires, Entre Ríos, Jujuy, La Pampa, Mendoza, Misiones, Santa Fe y San Luis. El objetivo es establecer cuáles son los diferentes patrones causales que explican los cambios políticos de jueces del STJ, y explicar esa diversidad de manera simple (Ragin 2007).

El análisis comparativo reveló la presencia de mecanismos de negociación y de cooptación en algunos casos de cambios políticos de jueces de la Corte, y esto permite explicar por qué la fragmentación legislativa no siempre impide cambios de jueces del STJ (Leiras, Giraudy y Tuñón 2015). En este sentido el trabajo realiza una contribución empírica y aporta evidencia que sostiene el argumento presentado sobre los mecanismos de negociación y cooptación, y sobre todo explicita los mecanismos causales que están detrás de los cambios de jueces en Argentina.

El artículo se organiza de la siguiente manera. La primera sección presenta el marco teórico, el concepto de cambio político de jueces de la Corte y los mecanismos causales propuestos. La segunda analiza características generales de los STJ en las provincias argentinas, cómo se designan y remueven los jueces del STJ, y las mayorías necesarias. La tercera explica el procedimiento seguido para confeccionar la tabla de datos. La cuarta presenta la tabla de verdad y los patrones causales detectados. La quinta analiza brevemente un caso por mecanismo, y al final se presentan las conclusiones.

\section{MARCO TEÓRICO, PROPUESTA Y ARGUMENTO}

Las Cortes judiciales son actores centrales en la política nacional y subnacional (Ward 2003; Bill Chavez 2004; Hilbink 2007; Whittington 2007; Smulovitz 2010; Castagnola 2012; Ingram 2012; Lara Borges, Castagnola y Pérez-Liñán 2012; Leiras, Giraudy y Tuñón 2015). Son órganos colegiados de conducción del Poder Judicial, y el Poder Judicial es una institución fundamental de la democracia (Helmke 2002; Iaryczower, Spiller y Tommasi 2002; Bill Chavez 
2004; O’Donnell 2004; Ríos Figueroa 2007; Pérez Liñán y Castagnola 2009; Lara Borges, Castagnola y Pérez Liñán 2012; Llanos, Tibi Weber, Heyl, y Stroh 2016). Las Cortes pueden frenar un proyecto o una política pública del gobierno, y según los casos inciden también en conflictos partidarios y electorales. Si bien las disputas políticas se dirimen habitualmente en la arena electoral, la judicial es fundamental porque los STJ tienen poder de decisión sobre cuestiones que son relevantes para la política provincial (o nacional, en su caso). Y por ese motivo los presidentes y gobernadores buscan ejercer influencia directa sobre las Cortes y expandir lealtades al interior del Poder Judicial (Lara Borges, Castagnola y Pérez-Liñán 2012).

En Argentina existe una rotación frecuente de jueces en los STJ provinciales y la literatura señala que los incentivos partidarios son un gran predictor de esos cambios en las Cortes (Castagnola 2010a, 2012; Leiras, Giraudy y Tuñón 2015). Sin embargo, no existe una clara relación entre estos cambios y el poder partidario de que disponen los gobernadores (Castagnola 2010a, 2012; Leiras, Giraudy y Tuñón 2015).

Castagnola propone la teoría de los "retiros inducidos" que sostiene que los jueces son inducidos a retirarse a través de estrategias y presiones informales por gobernadores que buscan crear una Corte aliada, y distingue entre estrategias institucionales y no institucionales (Castagnola 2010a, 2012). Las estrategias no institucionales, como reconoce Castagnola (2010a), tienen dos desventajas importantes: (a) no garantizan el resultado buscado (renuncia de jueces); y (b) pueden implicar mucho más tiempo y recursos que una destitución u otra estrategia institucional (Castagnola 2010a:35).

Ahora bien, la teoría de los retiros inducidos (Castagnola 2010a) enfoca el problema de manera tal que oscurece el rol de la oposición, de la legislatura, y de los líderes partidarios opositores. Para remover jueces de las Cortes eran necesarios dos tercios de bancas legislativas en veintidós (22) de las veinticuatro (24) provincias argentinas en 2009 (Castagnola 2010b:182), con lo cual rara vez un gobernador dispuso con su partido de la mayoría necesaria para remover jueces del STJ. Sin esa mayoría los incentivos partidarios se diluyen porque el gobernador debe negociar con otros actores, ya que las estrategias no institucionales no garantizan las renuncias y vacantes. Pero a pesar de esto los cambios en los STJ fueron frecuentes y la evidencia cuantitativa no muestra una relación clara entre el poder partidario del gobernador y los cambios de jueces del STJ (Castagnola 2010a, 2012; Leiras, Giraudy y Tuñón 2015).

En este trabajo se argumenta que los jueces siempre enfrentan presiones y no sólo del titular del ejecutivo, pero ello no necesariamente lleva a la renuncia de un juez a su cargo en el STJ. Las estrategias no institucionales que puede utilizar el gobernador sólo pueden prosperar cuando no existen líderes partidarios que respalden políticamente a esos jueces y puedan sostenerlos en sus puestos. Sin ese respaldo político difícilmente los jueces del STJ resistan las presiones del gobernador $\mathrm{u}$ otros actores poderosos. Esa ausencia de respaldo político es 
lo que genera el terreno adecuado para que prosperen las estrategias no institucionales de los gobernadores para generar vacantes en las Cortes. Pero el factor decisivo no son las presiones del gobernador, como sostiene Castagnola (2010a), sino el respaldo político que logra reunir para dar credibilidad a esas presiones y desplegar represalias.

El concepto de "cambio político de jueces del STJ" se refiere a aquellos casos en los que hay una modificación en la composición de la Corte que altera el balance de poder partidario al interior de la máxima instancia judicial. Para establecer cuándo hubo un cambio político de jueces del STJ se trabajó con dos indicadores: (a) el cambio en la pertenencia partidaria de la mayoría de jueces del STJ; o bien cuando (b) no cambia la pertenencia partidaria de la mayoría que prevalece en la Corte, pero cambia más del cincuenta por ciento (50\%) de la composición del STJ. Este segundo indicador permite identificar casos en que, sin alternancia partidaria, y por tanto sin incentivos partidarios de por medio, hay una reestructuración profunda del STJ. Ello implica que, aunque gobierne el mismo partido, las reestructuraciones de la Corte por disputas entre facciones partidarias son capturadas por el concepto de "cambio político del STJ."

Más allá de los momentos de cambios de jueces de los STJ, también son relevantes para el argumento desarrollado en este artículo los períodos en los cuales no hay un cambio político en el STJ pero sí es posible observar presiones sistemáticas del gobernador para modificar la Corte. Si bien en estos casos no hay cambio político del STJ, sí se trata de casos relevantes para esta teoría porque muestran los límites de las presiones del gobernador cuando no tiene respaldo político para desplegar represalias contra jueces de la Corte.

Aquí se entiende por facciones partidarias a los grupos internos de los partidos que, sobre la base del control de ciertos recursos, compiten por espacios de poder y candidaturas del partido (Leiras 2007:65), y cuyos miembros comparten un sentido de identidad y actúan en forma colectiva para alcanzar sus objetivos (Zariski [1960: 33], citado en Boucek 2009:14). ${ }^{2}$

En función de este planteo estratégico, este trabajo propone cuatro mecanismos causales para explicar los cambios políticos de jueces del STJ: (1) Imposición; (2) Negociación; (3) Cooptación; y (4) Bloqueo. Los tres primeros explican los cambios de jueces en los STJ de acuerdo al contexto político, en términos de gobierno mayoritario o minoritario (Cuadro 1). El cuarto mecanismo explica los intentos fallidos de cambio político de jueces de la Corte. 
Cuadro 1. Mecanismos causales y cambios de jueces del STJ

\begin{tabular}{|c|c|c|}
\hline $\begin{array}{l}\text { Mecanismo } \\
\text { Causal }\end{array}$ & Contexto político & Resultado STJ \\
\hline Imposición & Gobierno mayoritario & $\begin{array}{l}\text { El gobernador designa a los jueces que prefiere en } \\
\text { el STJ sin necesidad de negociar }\end{array}$ \\
\hline Negociación & $\begin{array}{l}\text { Gobierno minoritario con } \\
\text { acuerdo partidario }\end{array}$ & $\begin{array}{l}\text { Se modifica la composición del STJ por negociación } \\
\text { y acuerdo entre diferentes partidos o facciones par- } \\
\text { tidarias }\end{array}$ \\
\hline Cooptación & $\begin{array}{l}\text { Poder partidario del gober- } \\
\text { nador cercano a umbral de } \\
\text { mayoría necesaria }\end{array}$ & $\begin{array}{l}\text { Se modifica la composición del STJ por cooptación } \\
\text { de legisladores individuales que respaldan la ini- } \\
\text { ciativa del gobernador }\end{array}$ \\
\hline Bloqueo & $\begin{array}{l}\text { Gobierno minoritario sin } \\
\text { acuerdo partidario }\end{array}$ & $\begin{array}{l}\text { A pesar de las presiones del gobernador, no hay } \\
\text { cambio en STJ }\end{array}$ \\
\hline
\end{tabular}

El mecanismo de imposición denota un contexto político de gobierno mayoritario donde el partido del gobernador dispone por sí solo de la mayoría necesaria para designar jueces en la Corte, y no necesita negociar con otros partidos o facciones partidarias (siempre que la mayoría de su partido efectivamente responda a su liderazgo). ${ }^{3}$

El mecanismo de negociación parte de una situación de gobierno minoritario. El partido del gobernador no dispone de la mayoría necesaria y entonces para designar jueces en la Corte necesita un acuerdo con otros partidos o facciones partidarias. La negociación puede ser entre diferentes partidos o entre facciones partidarias de diferentes partidos.

El mecanismo de cooptación también parte de un contexto de gobierno minoritario. La diferencia principal con el de negociación es que el partido del gobernador reúne un porcentaje de bancas legislativas muy cercano a la mayoría necesaria, y puede cooptar el voto de uno o unos pocos legisladores individuales para alcanzar la mayoría necesaria para designar a los jueces de su preferencia en el STJ.

En los tres mecanismos se hizo referencia a la mayoría para designar jueces del STJ, pero también se aplican a la remoción de jueces de las Cortes. Si un gobernador dispone de dos tercios, puede destituir un juez del STJ sin negociar con otros actores. Si el partido del gobernador reúne la mayoría para designar un juez del STJ pero no para remover, debe negociar con otros partidos o facciones partidarias, o cooptar a algunos legisladores individuales.

Por último, el mecanismo del bloqueo explica los intentos fallidos de cambio político en el STJ por parte de gobernadores que, aunque tienen la intención de 
modificar la Corte y presionan a los jueces para forzar su salida, no consiguen cambiar la composición de la máxima instancia judicial.

En la siguiente sección se analizan las características generales de los STJ en las provincias argentinas, las mayorías para designar y remover jueces del STJ y el poder partidario de gobernadores.

\section{LOS STJ EN LAS PROVINCIAS ARGENTINAS: CARACTERÍSTICAS GENERALES Y MAYORÍAS PARA NOMBRAR Y REMOVER JUECES DE LAS CORTES.}

Las provincias argentinas dictan su propia constitución bajo el sistema representativo republicano que, entre otras cosas, debe asegurar su administración de justicia (art. 5 de la Constitución Nacional -CN). Ejercen todo el poder no delegado al gobierno nacional, dictan sus propias instituciones y se rigen por ellas, dictan sus leyes electorales, su régimen municipal, su administración de justicia, y eligen gobernadores y legisladores sin intervención del gobierno nacional. Existe una vasta literatura que aborda la variabilidad de las prácticas políticas e instituciones democráticas al interior de grandes países federales (Behrend y Whitehead 2017), y específicamente sobre la Argentina (Gervasoni 2010; Behrend 2011).

Cada provincia (23 provincias y la Ciudad Autónoma de Buenos Aires) tiene su propia constitución local que contempla un STJ como máxima autoridad judicial en su territorio. Además, dictan su propia ley orgánica del Poder Judicial, y si bien no pueden dictar normas de fondo (art. $126 \mathrm{CN}$ ) sí pueden dictar sus propias normas procesales. Los STJ, como máxima autoridad provincial del Poder Judicial, tienen poder de decisión sobre cuestiones que son relevantes para la política provincial (o nacional, en su caso). Las decisiones de las Cortes pueden impactar sobre proyectos o políticas públicas del gobierno. ${ }^{4}$ Pueden afectar las asignaciones presupuestarias y la realización de obras, las disputas entre diversos poderes del Estado, y según los casos también inciden en conflictos partidarios y electorales. ${ }^{5}$ Los STJ realizan control de constitucionalidad de los actos de gobierno, tienen decisión sobre conflictos judiciales que involucran al Estado provincial y los municipios, cuestiones de competencia electoral y disputas entre partidos políticos, todo lo cual los convierte en actores relevantes para la política provincial. ${ }^{6}$

\footnotetext{
En agosto de 2016 la Corte Suprema de Justicia de la Nación frenó los aumentos en la tarifa del servicio del gas para usuarios residenciales.

En noviembre de 2005 la jueza que presidía el STJ misionero resolvió tres disputas de modo contrario a los intereses del gobernador: otorgó una banca a un diputado provincial opositor, a un concejal de una lista opositora, y convalidó la destitución de un intendente aliado del gobernador (Abdulhadi 2016:363-364).

Para una revisión de la literatura que analiza los modelos con los cuales se estudia cómo deciden los jueces, incluyendo la que vincula el partido político de nombramiento de jueces con la forma en que fallan, puede verse el trabajo de Basabe Serrano (2008). El trabajo de Castagnola (2010a, 2012) sostiene que más importante que el partido es la facción partidaria, y la proximidad del juez con la facción del gobernador.
} 
La forma en que están organizados los STJ varía de una provincia a otra, tanto si se organizan en Salas o no, como en relación con la cantidad de jueces que integran cada Corte. Los jueces que integran las Cortes provinciales son elegidos, en todos los casos, de manera indirecta (Castagnola 2008) en la medida que la ciudadanía no participa a través de elecciones como sucede con el Poder Ejecutivo y el Poder Legislativo. A modo de ejemplo se presenta en el Cuadro 2 una comparación esquemática de los procedimientos de designación de las provincias en las que se basa este artículo. ${ }^{7}$

Cuadro 2. Procedimientos de designación STJ y actores involucrados en el nombramiento (provincias seleccionadas)

\begin{tabular}{lc}
\hline Provincia & Procedimiento de designación \\
\hline Chaco & PE a propuesta del CM \\
Chubut & PE con acuerdo del PL \\
Ciudad de Buenos Aires & PE con acuerdo del PL \\
Entre Ríos & PE con acuerdo del SP \\
Jujuy & PE con acuerdo de PL \\
La Pampa & PE con acuerdo de PL \\
Mendoza & PE con acuerdo del SP \\
Misiones & PE con acuerdo de PL \\
San Luis & PE con acuerdo del SP \\
Santa Fe & PE con acuerdo de la AL \\
\hline
\end{tabular}

Fuente: elaboración propia en base a las constituciones provinciales y Castagnola (2008, 2010b). PE: Poder Ejecutivo; PL: Poder Legislativo; CM: Consejo de la Magistratura; SP: Senado provincial; AL: Asamblea Legislativa (diputados y senadores provinciales).

Los gobernadores tienen el rol principal en el nombramiento de jueces del STJ, con la excepción de Chaco donde formalmente es el Consejo de la Magistratura el que elige. ${ }^{8}$ A esto se agregan dos variables clave: las mayorías requeridas para designar jueces de la Corte y para destituirlos.

Si bien existe una gran heterogeneidad entre las provincias argentinas respecto a los diseños institucionales de los STJ, especialmente en cuanto a procedimientos de designación y mayorías requeridas (Castagnola 2008, 2010b), todas las provincias exigen mayorías calificadas para destituir jueces del STJ por la vía del juicio político. Aunque existe cierta diversidad en los procedimientos constitucionales previstos en las provincias para llevar adelante un juicio po-

La metodología y selección de casos se analiza en la sección 4 del presente.

Este artículo no estudia cómo eligen los gobernadores a quién nombrar juez del STJ. Castagnola (2012) sugiere que a nivel subnacional en Argentina las lealtades pueden ser más personales entre gobernadores y jueces del STJ. Aquí se asume que el gobernador elegirá al juez que prefiera para el STJ, y se analizan las condiciones en que podrá o no lograrlo (imposición, negociación, cooptación o bloqueo). 
lítico, en todos los casos se exigen 2/3 para acusar y para destituir jueces del STJ. Respecto a las causales de juicio político para remover un juez de la Corte, suelen ser restrictivas (Castagnola 2008), y es bajo el porcentaje de remoción por juicio político como demuestra Castagnola (2010a, 2012). Sin embargo, en todas las provincias existen causales de "mal desempeño", "mal desempeño de las funciones" o "incumplimiento de los deberes" a su cargo (Castagnola 2008), y como evidencian algunos casos de juicio político (Abdulhadi 2016), pueden dar lugar a discrecionalidades del órgano que juzga. Castagnola (2012) muestra que la cantidad de remociones de jueces del STJ por juicio político es baja, pero es muy alta la remoción por "amenaza de juicio de político" o "renuncia durante un proceso de juicio político."

Ahora bien, en cuanto a las mayorías para designar jueces de las Cortes hay mayor heterogeneidad entre provincias (Castagnola 2008, 2010b), y también algunas variaciones a lo largo del tiempo. Por ejemplo, en Misiones entre 1983 y 2000 se exigía mayoría absoluta para designar un juez de la Corte, pero desde el año 2001 se ratificó una enmienda constitucional que elevó esa mayoría a 2/3 para designar un juez del STJ. En Chaco se exige mayoría absoluta dentro del Consejo de la Magistratura (cuatro votos sobre un total de siete representantes) y en Santa Fe mayoría absoluta de la Asamblea legislativa (Cuadro 3).

Cuadro 3. Evolución de mayorías para designar jueces STJ por provincia 1983-2011

\begin{tabular}{lccccccc}
\hline Provincia & $\mathbf{8 3 - 8 7}$ & $\mathbf{8 7 - 9 1}$ & $\mathbf{9 1 - 9 5}$ & $\mathbf{9 5 - 9 9}$ & $\mathbf{9 9 - 2 0 0 3}$ & $\mathbf{2 0 0 3 - 2 0 0 7}$ & 2007-2011 \\
\hline CABA & - & - & - & $2 / 3$ & $2 / 3$ & $2 / 3$ & $2 / 3$ \\
Chaco & MA & MA & MA & MA & MA & MA & MA \\
Chubut & MA & MA & MA & $2 / 3$ & $2 / 3$ & $2 / 3$ & $2 / 3$ \\
Entre Ríos & MA & MA & MA & MA & MA & MA & MA \\
Jujuy & MS & MS & MS & MS & MS & MS & MS \\
La Pampa & MS & MS & MS & MS & MS & MS & MS \\
Mendoza & MS & MS & MS & MS & MS & MS & MS \\
Misiones & MA & MA & MA & MA & $2 / 3$ & $2 / 3$ & $2 / 3$ \\
San Luis & MA & MA & MA & MA & MA & MA & MA \\
Santa Fe & MA & MA & MA & MA & MA & MA & MA \\
\hline
\end{tabular}

Fuente: Elaboración propia en base a Castagnola (2008, 2010b), y Constituciones provinciales. MS = mayoría simple; MA = mayoría absoluta

Como el poder partidario del gobernador es una variable central del planteo que aquí se presenta, se elaboró un cuadro con el porcentaje de bancas de que dispuso el partido o coalición del gobernador en cada provincia para establecer en cada momento si contaba con la mayoría necesaria para designar jueces del STJ, y para destituirlos, porque esto informa si dispuso de la amenaza de des- 


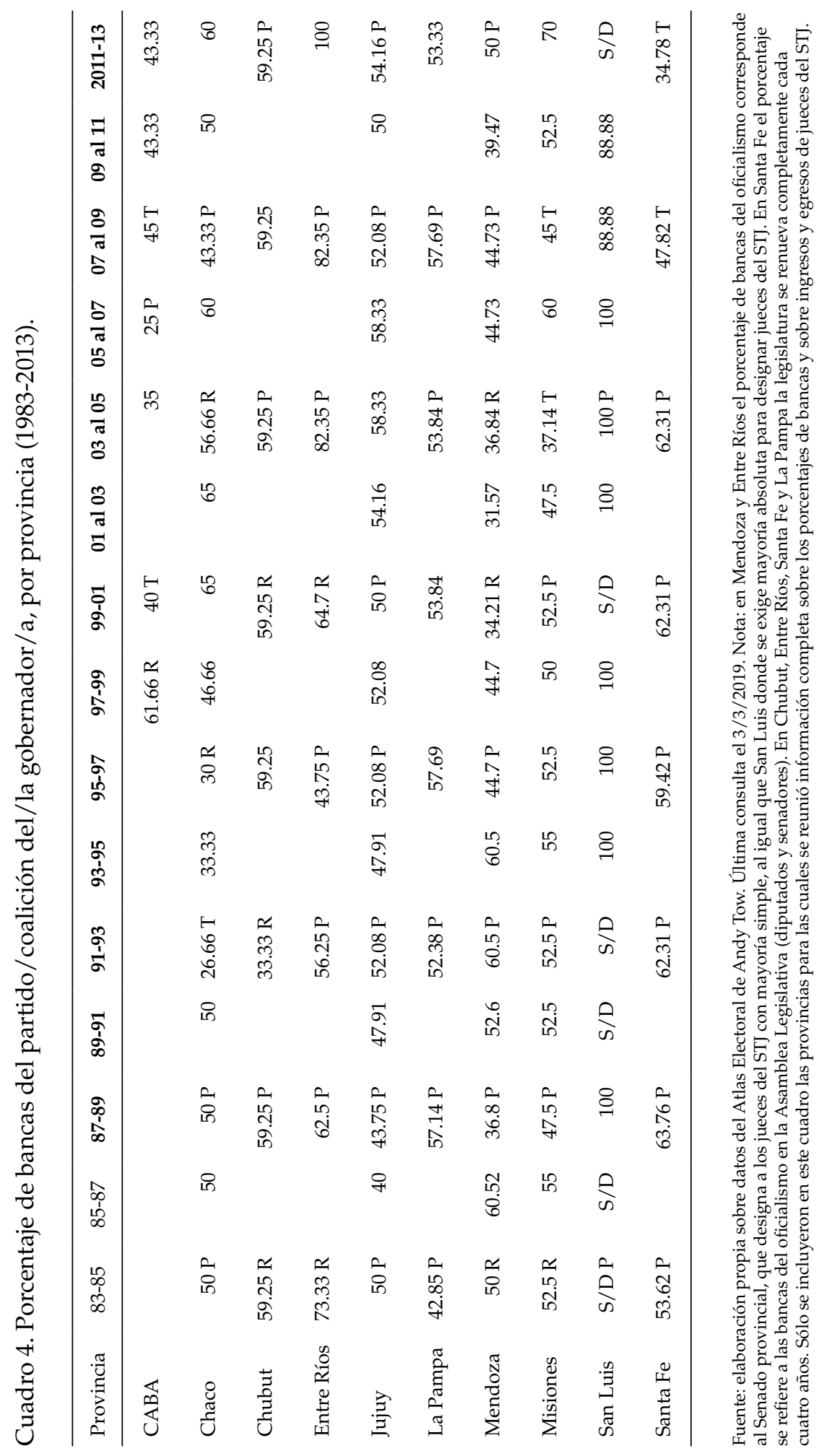


titución (Cuadro 4). ${ }^{9}$ Puede ocurrir que el partido del gobernador reúna la mayoría para designar un juez en la Corte pero no para removerlo, en cuyo caso para cambiar el STJ debe negociar con otros partidos o facciones partidarias, $\mathrm{o}$ cooptar a algunos legisladores individuales.

Otras variables independientes relevantes son la alternancia partidaria y la alternancia ejecutiva. Para distinguir en el Cuadro 4 cuándo hubo alternancia partidaria se utilizó la letra " $\mathrm{R}$ " para el partido radical, la letra " $\mathrm{P}$ " para gobernadores del peronismo y la letra " $\mathrm{T}$ " para terceras fuerzas, generalmente partidos o coaliciones de alcance provincial. Si un gobernador fue reelecto no se colocó ninguna letra en la celda correspondiente.

En la próxima sección se explica la metodología y el procedimiento seguido para codificar los cambios de jueces de las Cortes.

\section{METODOLOGÍA Y PROCEDIMIENTO PARA CODIFICAR CAMBIOS DE JUECES EN LOS STJ PROVINCIALES Y ELABORAR LA TABLA DE DATOS}

Todas las provincias argentinas se analizaron a partir del cruce entre el poder partidario de los gobernadores (porcentaje de bancas legislativas de su partido) y las mayorías exigidas por los diseños institucionales para nombrar y remover jueces de las Cortes.

En cuanto a las técnicas de recolección de datos, este trabajo está basado en los siguientes elementos:

a) Desarrollo de una base de datos original con información sobre el porcentaje de bancas legislativas del partido del gobernador, y sobre la existencia de alternancia partidaria o no, para cada provincia entre 1983-2011, utilizando datos del Atlas Electoral de Andy Tow. ${ }^{10}$

b) Desarrollo de una base de datos original con información sobre la totalidad de jueces que integraron las Cortes provinciales de los casos estudiados, con indicación de las fechas de ingreso y egreso del cargo. Aquí se incluyeron sólo las diez provincias para las cuales se pudo obtener información completa.

c) Elaboración de una base de datos propia con información, obtenida de fuentes secundarias, sobre la evolución de los diseños institucionales del STJ por provincia durante el período estudiado, para establecer qué tipo de mayoría se exigía en cada provincia en cada momento para designar y remover jueces de la Corte, y determinar si el partido del gobernador contaba con la mayoría legislativa necesaria.

Los porcentajes de bancas del partido del gobernador reflejan la cantidad de legisladores que ingresaron por las listas del oficialismo en cada elección, y no incluyen realineamientos o cambios en la composición de los bloques legislativos que hubieran ocurrido entre elecciones.

10 Acceso online en www.andytow.com. Última consulta 3/3/2019. 
d) Trabajo de hemeroteca. Se revisaron los principales diarios provinciales en cada uno de los casos analizados en profundidad, para identificar las principales facciones partidarias en cada provincia y analizar los momentos de cambio político de jueces de los STJ. El trabajo de hemeroteca se focalizó en las fechas de ingreso y egreso de jueces de las Cortes, y sirvió para determinar la filiación partidaria de los candidatos a jueces de las Cortes promovidos por los gobernadores. El trabajo se complementó también con fuentes secundarias, informes oficiales y bibliografía existente.

Un factor clave del análisis comparativo enfocado en la diversidad es la selección del resultado a estudiar y la especificación de las condiciones causales relevantes para la explicación de ese resultado (Ragin 2007). En este trabajo el resultado es el cambio político de jueces del STJ.

Se analizaron todos los cambios de jueces del STJ para detectar los casos motivados por razones políticas, es decir cuando un juez fue forzado a renunciar, para distinguirlo de los egresos y reemplazos no basados en motivos políticos (por ejemplo, por fallecimiento, decisión personal, jubilación por problemas de salud). Este análisis de todos los casos individuales permitió establecer cuándo hubo renuncias forzadas por motivos políticos. Cuando se reemplazó un solo juez en la Corte se tomó en cuenta la composición total del STJ para determinar si hubo cambio político o no. Por ejemplo, el reemplazo de un solo juez en el STJ misionero en 1997 no alteró el balance partidario en esa Corte de nueve miembros, y no se codificó como cambio político.

Este procedimiento de codificación implica que un reemplazo de un solo juez del STJ puede tener una fuerte connotación partidaria, pero si no alteró el balance político partidario prevaleciente en la Corte no se codificó como cambio político de jueces del STJ. Por ejemplo, en Chaco en el año 2006 se incorporó al STJ el jefe de gabinete del gobernador radical, pero no se codificó como cambio político de jueces porque no alteró la mayoría partidaria prevaleciente, sino que en todo caso la reforzó.

Por otra parte, como la jubilación constituye una estrategia no institucional (Castagnola 2010a) utilizada por los gobernadores para que un juez se retire, se analizaron detenidamente los retiros por jubilación. Cuando se detectó más de un juez que se retiró por jubilación en el mismo período de un gobernador se acudió al trabajo de hemeroteca y si la evidencia lo justificaba, se codificó como cambio político de jueces del STJ. Por ejemplo, el retiro por jubilación especial de cuatro jueces del STJ entrerriano en 2000 se codificó como cambio político de jueces del STJ, al igual que el retiro por jubilación de cuatro miembros del STJ misionero en 2006. En cambio, la jubilación de un juez de la Corte de la Ciudad de Buenos Aires en 2009, como caso aislado, no se tomó como cambio político de jueces del STJ para el período 2007-2011.

Además, el timing se consideró clave para comprender cambios políticos de jueces del STJ porque esos cambios no siempre ocurren de manera simultánea. 
Por ese motivo, y por las variaciones al interior de cada provincia a lo largo del tiempo, en la tabla de datos se tomó como unidad de análisis la provincia-período de gobierno, y no la provincia en sí misma: Misiones 1987-1991, Misiones 1991-1995, Chaco 1991-1995, Entre Ríos 1995-1999, y así sucesivamente con cada provincia analizada en este trabajo. El período 1983-1987 se consideró como línea de base, por lo cual se agruparon los demás períodos por provincia desde 1987 y hasta $2011 .^{11}$

En la tabla de datos se colocaron todas las unidades de análisis y en diferentes columnas las variables independientes. En la última columna se colocó la variable dependiente (cambio político del STJ). Las variables se tomaron como dicotómicas por lo cual se colocó uno para indicar presencia (1) y cero para indicar ausencia (0). Las variables independientes son: (a) Alternancia partidaria; (b) Alternancia ejecutiva; (c) Mayoría para designar jueces del STJ; (d) Mayoría para remover jueces del STJ; y (e) Acuerdo político. ${ }^{12}$

La variable "Acuerdo político" sintetiza en una sola columna los mecanismos de negociación y de cooptación. Para elaborar la tabla de verdad se consideró suficiente identificar si el gobernador tuvo respaldo de otros bloques legislativos más allá de su partido, independientemente de si se trató de negociación o de cooptación. El objetivo era detectar las configuraciones causales en las que los gobernadores tuvieron respaldo de otros bloques legislativos para realizar un cambio político del STJ.

La primera tabla de datos elaborada mostró inconsistencias porque con idénticas configuraciones causales se detectaron resultados diferentes en la variable dependiente, y esto obliga a revisar las variables independientes (Ragin 2007). Sobre las treinta y dos (32) combinaciones causales lógicamente posibles, la tabla de datos reunía trece (13) configuraciones existentes, de las cuales cinco mostraban al menos un caso inconsistente.

Por estas inconsistencias se revisaron en detalle los casos específicos y las variables independientes, y de ese análisis surgieron algunos cambios metodológicos para elaborar una nueva tabla de datos.

En primer lugar, la variable "mayoría para remover jueces del STJ" no diferenciaba configuraciones causales ya que en casi todos los casos tenía el mismo valor (cero). Los gobernadores rara vez reunieron con su propio partido los dos tercios de la legislatura por lo cual esta variable aportaba poco a una tabla de verdad. Sin embargo, ello no implica que no sea una variable relevante, sino que como el umbral requerido para destituir un juez del STJ es alto (dos

11 La Ciudad de Buenos Aires sancionó su Constitución en 1996 por lo cual el período va de 1999 a 2011. Además, por la destitución del gobernador que tuvo lugar en 2005, el período 2003-2007 fue subdividido en dos: 1) 2003-2005 bajo un gobernador; y 2) 2005-2007 con otro gobernador.

12 Si bien la legitimidad de los jueces de la Corte es una variable clave (Walker 2017), no se incluyó en este trabajo por la ausencia de información disponible (encuestas, sondeos) sobre los jueces de las Cortes estudiadas. 
tercios), cobran relevancia otras variables como el "Acuerdo político", que sintetiza los mecanismos de negociación y de cooptación.

En segundo lugar, las estrategias institucionales que analiza Castagnola (2010a, 2012) también permiten sortear la mayoría para destituir un juez del STJ, y sin necesidad de un acuerdo político (sea de negociación o de cooptación). Dentro de las estrategias institucionales (Castagnola 2010a) destacaron especialmente dos: (a) la ampliación del tamaño del STJ (court-packing) y (b) las jubilaciones especiales. La ampliación del STJ permite sumar nuevos miembros sin remover los existentes, y producir un cambio político. Las jubilaciones especiales funcionan como catalizadoras de renuncias de jueces del STJ y si el gobernador dispone de la mayoría necesaria puede designar nuevos jueces sin negociación ni cooptación.

A la luz de la evidencia anterior, se decidió reemplazar la variable "mayoría para destituir un juez del STJ" por una variable que representara las estrategias institucionales (Castagnola 2010a, 2012). Con este cambio en las variables independientes se revisó nuevamente la codificación de todos los casos para asegurar que el procedimiento se replicara de manera idéntica en toda la tabla de datos. La tabla resultante (Tabla 1) se muestra completa a continuación, para analizarla luego en detalle y realizar la simplificación de sus términos (Ragin 2007).

Tabla 1: variables para cada provincia analizada

\begin{tabular}{lcccccc}
\hline Casos provinciales & $\begin{array}{c}\text { Alt. } \\
\text { Partidaria }\end{array}$ & $\begin{array}{c}\text { Alt. } \\
\text { Ejecutiva }\end{array}$ & $\begin{array}{c}\text { Mayoría p/ } \\
\text { designar }\end{array}$ & EI $^{*}$ & $\begin{array}{c}\text { Acuerdo } \\
\text { Político }\end{array}$ & $\begin{array}{c}\text { Cambio } \\
\text { político STJ }\end{array}$ \\
\hline CABA 1999-2003 & 0 & 1 & 0 & 0 & 0 & 0 \\
CABA 2003-2005 & 1 & 0 & 0 & 0 & 1 & 0 \\
CABA 2005-2007 & 1 & 1 & 0 & 0 & 0 & 0 \\
CABA 2007-2011 & 1 & 1 & 0 & 0 & 0 & 0 \\
Chaco 1987-91 & 0 & 1 & 1 & 0 & 0 & 0 \\
Chaco 1991-95 & 1 & 1 & 0 & 0 & 0 & 0 \\
Chaco 1995-99 & 1 & 1 & 1 & 0 & 0 & 1 \\
Chaco 1999-03 & 0 & 0 & 1 & 0 & 0 & 0 \\
Chaco 2003-2007 & 0 & 1 & 1 & 0 & 0 & 0 \\
Chaco 2007-2011 & 1 & 1 & 0 & 0 & 0 & 0 \\
Chubut 1987-91 & 1 & 1 & 1 & 0 & 0 & 1 \\
Chubut 1991-95 & 1 & 1 & 0 & 0 & 0 & 0 \\
Chubut 1995-99 & 0 & 0 & 0 & 0 & 0 & 0 \\
Chubut 1999-03 & 0 & 1 & 0 & 0 & 0 & 0 \\
Chubut 2003-07 & 1 & 1 & 0 & 1 & 1 & 1 \\
Chubut 2007-11 & 0 & 0 & 0 & 0 & 0 & 0 \\
Entre Ríos 1987-91 & 1 & 1 & 1 & 1 & 0 & 0 \\
Entre Ríos 1991-95 & 0 & 1 & 1 & 0 & 0 & 1 \\
Entre Ríos 1995-99 & 0 & 1 & 0 & 0 & 0 & 0 \\
\hline & & & & & & \\
\hline
\end{tabular}




\begin{tabular}{|c|c|c|c|c|c|c|}
\hline Casos provinciales & $\begin{array}{c}\text { Alt. } \\
\text { Partidaria }\end{array}$ & $\begin{array}{c}\text { Alt. } \\
\text { Ejecutiva }\end{array}$ & $\begin{array}{c}\text { Mayoría p/ } \\
\text { designar }\end{array}$ & $\mathbf{E I}^{*}$ & $\begin{array}{c}\text { Acuerdo } \\
\text { Político }\end{array}$ & $\begin{array}{c}\text { Cambio } \\
\text { político } S T]\end{array}$ \\
\hline Entre Ríos 1999-03 & 1 & 1 & 1 & 1 & 0 & 1 \\
\hline Entre Ríos 2003-07 & 1 & 1 & 1 & 0 & 0 & 1 \\
\hline Entre Ríos 2007-11 & 0 & 1 & 1 & 0 & 0 & 0 \\
\hline Jujuy 1987-91 & 0 & 1 & 1 & 0 & 0 & 0 \\
\hline Jujuy 1991-95 & 0 & 1 & 1 & 0 & 0 & 0 \\
\hline Jujuy 1995-99 & 0 & 1 & 1 & 0 & 0 & 0 \\
\hline Jujuy 1999-03 & 0 & 1 & 1 & 0 & 0 & 0 \\
\hline Jujuy 2003-07 & 0 & 0 & 1 & 0 & 1 & 1 \\
\hline Jujuy 2007-11 & 0 & 1 & 1 & 0 & 0 & 0 \\
\hline La Pampa 1987-91 & 0 & 1 & 1 & 0 & 0 & 0 \\
\hline La Pampa 1991-95 & 0 & 1 & 1 & 1 & 0 & 1 \\
\hline La Pampa 1995-99 & 0 & 0 & 1 & 0 & 0 & 0 \\
\hline La Pampa 1999-03 & 0 & 0 & 1 & 0 & 0 & 0 \\
\hline La Pampa 2003-07 & 0 & 1 & 1 & 0 & 0 & 0 \\
\hline La Pampa 2007-11 & 0 & 1 & 1 & 0 & 0 & 0 \\
\hline Mendoza 1987-91 & 1 & 1 & 0 & 0 & 0 & 0 \\
\hline Mendoza 1991-95 & 0 & 1 & 1 & 0 & 0 & 0 \\
\hline Mendoza 1995-99 & 0 & 1 & 0 & 0 & 0 & 0 \\
\hline Mendoza 1999-03 & 1 & 1 & 0 & 0 & 0 & 0 \\
\hline Mendoza 2003-07 & 0 & 1 & 0 & 0 & 0 & 0 \\
\hline Mendoza 2007-11 & 1 & 1 & 0 & 0 & 0 & 0 \\
\hline Misiones 1987-91 & 1 & 1 & 1 & 1 & 0 & 1 \\
\hline Misiones 1991-95 & 0 & 1 & 1 & 0 & 0 & 0 \\
\hline Misiones 1995-99 & 0 & 0 & 1 & 0 & 0 & 0 \\
\hline Misiones 1999-03 & 0 & 1 & 0 & 0 & 0 & 0 \\
\hline Misiones 2003-2007 & 1 & 0 & 0 & 1 & 1 & 1 \\
\hline Misiones 2007-2011 & 0 & 1 & 0 & 0 & 0 & 0 \\
\hline San Luis 1987-91 & 0 & 0 & 1 & 0 & 0 & 0 \\
\hline San Luis 1991-95 & 0 & 0 & 1 & 1 & 0 & 1 \\
\hline San Luis 1995-99 & 0 & 0 & 1 & 1 & 0 & 1 \\
\hline San Luis 1999-03 & 0 & 0 & 1 & 0 & 0 & 0 \\
\hline San Luis 2003-07 & 0 & 1 & 1 & 0 & 0 & 0 \\
\hline San Luis $2007-11$ & 0 & 0 & 1 & 0 & 0 & 0 \\
\hline Santa Fe 1987-91 & 0 & 1 & 1 & 0 & 1 & 1 \\
\hline Santa Fe 1991-95 & 0 & 1 & 1 & 0 & 0 & 0 \\
\hline Santa Fe 1995-99 & 0 & 1 & 1 & 0 & 0 & 0 \\
\hline Santa Fe 1999-03 & 0 & 1 & 1 & 0 & 1 & 1 \\
\hline Santa Fe 2003-2007 & 0 & 1 & 1 & 0 & 0 & 0 \\
\hline Santa Fe 2007-2011 & 1 & 1 & 0 & 0 & 0 & 0 \\
\hline
\end{tabular}

*Nota: la abreviatura "EI" resume la variable "Estrategia Institucional" que está tomada del trabajo de Castagnola $(2010 a, 2012)$. 
$\mathrm{Al}$ establecer como unidad de análisis la provincia-período de gobierno, en la Tabla 1 se conformaron en total 58 casos, que surgen de diez provincias (nueve provincias con seis períodos de gobierno entre 1987 y 2011, más cuatro períodos de gobierno de la Ciudad de Buenos Aires).

En esta segunda tabla de datos, ajustada con la corrección de la variable "estrategia institucional," subsistían sólo tres casos que rompían las configuraciones causales, pero que pudieron ser resueltos a partir de un análisis más detallado: Jujuy 2003-2007; Entre Ríos 1987-1991 y Entre Ríos 1991-1995. A continuación, se discuten estos casos para explicar el ajuste realizado en la tabla de datos.

\section{Jujuy 2003-2007}

Jujuy entre 2003-2007 tuvo cambio político del STJ porque se designaron tres nuevos jueces sobre un total de cinco. Sin embargo, era el único caso inconsistente en la configuración causal correspondiente. Se revisó en detalle el caso y se detectaron tres motivos para rectificar la codificación en la tabla de datos.

El primero es que el partido del gobernador (PJ) tenía apoyo de otras bancadas en la legislatura porque logró aprobar el inicio del juicio político a un juez del STJ (Diario El Pregón, 6/8/2004) para lo cual necesitaba dos tercios (el juez renunció el mismo día).

El segundo es que el gobernador peronista tuvo apoyo de legisladores radicales para aprobar la designación de dos funcionarios cercanos a su liderazgo como jueces del STJ (Diario El Pregón, 11 y 12/11/2004). En ambas ocasiones operó el mecanismo de negociación.

El tercero es que dos legisladores radicales facilitaron el quórum que necesitó el partido del gobernador para aprobar, entre otras iniciativas, la designación de un candidato del oficialismo para juez del STJ en la última sesión del año 2007 (Diario El Pregón, 29/12/2007). ${ }^{13}$ En esta oportunidad operó el mecanismo de cooptación, porque la sesión legislativa fue interrumpida hasta que llegaron dos legisladores radicales que facilitaron con su presencia el quórum para continuar la sesión (Diario El Pregón, 29/12/2007).

Por ello se colocó uno (1) en la celda de la variable "acuerdo político" para Jujuy 2003-2007, y al hacerlo se eliminó la inconsistencia en la configuración causal.

\section{Entre Ríos 1987-1991 y 1991-1995}

La provincia de Entre Ríos en los períodos 1987-1995 revela el problema del timing al que se hizo referencia en esta sección. El cambio político del STJ se

13 La vacante cubierta a fines de 2007 se produjo en septiembre de 2005 cuando falleció un integrante del STJ (El Pregón, 20/9/2005). Sin embargo, se cubrió recién el 29/12/2007. 
produjo durante el período del gobernador Mario Moine (PJ, 1991-1995) pero en realidad se inició bajo el gobierno de Jorge Busti (PJ, 1987-1991), líder del peronismo entrerriano que fue nuevamente gobernador entre 1995-1999 y entre 2003-2007.

El gobernador Busti (1987-1991) encontró en su primer mandato un STJ de siete miembros, todos designados por su antecesor radical Sergio Montiel (19831987). Busti no pudo cambiar el STJ pero sí promovió una ley que amplió la cantidad de miembros a nueve y designó dos nuevos jueces del STJ, cercanos a su liderazgo. Por ello en la tabla de datos se colocó el número 1 en la variable "estrategia institucional" y un cero en la columna de la variable dependiente porque los dos nuevos jueces designados por Busti no alteraron la mayoría prevaleciente en el STJ.

En el mandato del gobernador Moine (1991-1995) se retiraron cuatro jueces del STJ que fueron reemplazados por nuevos jueces designados por el peronismo. A partir del análisis realizado sobre la provincia de Entre Ríos se decidió colocar un cero (0) en la variable "estrategia institucional" (EI) para el caso de Entre Ríos 1987-1991, pero sí asentar el uno (1) en la variable EI para Entre Ríos 1991-1995 que fue cuando se produjo el cambio político en el STJ. En la sección siguiente se discuten los patrones causales detectados con la tabla de verdad.

\section{TABLA DE VERDAD}

Con los 58 casos construidos en la tabla de datos (Tabla 1) se identificaron quince configuraciones causales. En siete configuraciones, que agrupan en total cuarenta y cuatro (44) casos, no hubo cambio político del STJ, mientras que sí lo hubo en las restantes ocho configuraciones que agrupan catorce casos. La tabla de verdad (Tabla 2) presenta las quince configuraciones causales ordenadas en filas distintas, y sintetiza la descripción de las configuraciones que existen en la tabla de datos (Tabla 1). Éste primer paso es importante porque ordena el análisis para distinguir patrones causales (Ragin 2007). Para esto se siguió el procedimiento de simplificación de la tabla de verdad propuesto por Ragin (2007:203-210), que permitió identificar cuatro patrones causales que condujeron a cambios políticos en los STJ.

Tabla 2. Tabla de verdad: configuraciones causales

\begin{tabular}{lccccccc}
\hline $\begin{array}{l}\text { Configuraciones } \\
\text { causales }\end{array}$ & $\begin{array}{c}\text { Alternancia } \\
\text { Partidaria }\end{array}$ & $\begin{array}{c}\text { Alternancia } \\
\text { Ejecutiva }\end{array}$ & $\begin{array}{c}\text { Mayoría p/ } \\
\text { designar }\end{array}$ & EI & $\begin{array}{c}\text { Acuerdo } \\
\text { Político }\end{array}$ & $\begin{array}{c}\text { Cambio } \\
\text { político STJ }\end{array}$ & $\begin{array}{c}\mathbf{N}^{\text {o }} \text { de } \\
\text { casos }\end{array}$ \\
\hline 1 & 0 & 1 & 1 & 0 & 0 & 0 & 17 \\
2 & 1 & 1 & 0 & 0 & 0 & 0 & 9 \\
3 & 0 & 1 & 0 & 0 & 0 & 0 & 7 \\
4 & 0 & 0 & 1 & 0 & 0 & 0 & 7 \\
\hline
\end{tabular}




\begin{tabular}{lccccccc}
\hline $\begin{array}{l}\text { Configuraciones } \\
\text { causales }\end{array}$ & $\begin{array}{c}\text { Alternancia } \\
\text { Partidaria }\end{array}$ & $\begin{array}{c}\text { Alternancia } \\
\text { Ejecutiva }\end{array}$ & $\begin{array}{c}\text { Mayoría p/ } \\
\text { designar }\end{array}$ & EI & $\begin{array}{c}\text { Acuerdo } \\
\text { Político }\end{array}$ & $\begin{array}{c}\text { Cambio } \\
\text { político STJ }\end{array}$ & $\begin{array}{c}\mathbf{N}^{\mathbf{o}} \text { de } \\
\text { casos }\end{array}$ \\
\hline 5 & 1 & 1 & 1 & 0 & 0 & 1 & 3 \\
6 & 0 & 1 & 1 & 1 & 0 & 1 & 2 \\
7 & 0 & 1 & 1 & 0 & 1 & 1 & 2 \\
8 & 1 & 1 & 1 & 1 & 0 & 1 & 2 \\
9 & 0 & 0 & 1 & 1 & 0 & 1 & 2 \\
10 & 0 & 0 & 0 & 0 & 0 & 0 & 2 \\
11 & 1 & 0 & 0 & 0 & 0 & 0 & 1 \\
12 & 1 & 0 & 0 & 1 & 1 & 1 & 1 \\
13 & 1 & 1 & 0 & 1 & 1 & 1 & 1 \\
14 & 1 & 1 & 1 & 0 & 0 & 0 & 1 \\
15 & 0 & 0 & 1 & 0 & 1 & 1 & 1 \\
\hline
\end{tabular}

El procedimiento de simplificación de las configuraciones implica que si dos filas de la tabla de verdad que tienen el mismo resultado (cambio político del STJ) difieren en una sola variable, entonces esa variable puede eliminarse porque no tiene un efecto distinguible en el resultado (Ragin 2007:205). Una forma sencilla de graficar la presencia o ausencia de la condición causal es a través de letras mayúsculas y minúsculas, donde las mayúsculas indican presencia de la variable mientras que las minúsculas su ausencia (Ragin 2007:203-2010). El Panel A ordena los casos de cambio político del STJ de acuerdo a sus configuraciones causales, e indica la presencia o ausencia de cada variable con letras mayúsculas y minúsculas.

Panel A. Casos de cambio político del STJ

\begin{tabular}{|c|c|}
\hline Fila & Configuraciones causales \\
\hline 5 & PARTIDARIA $\times$ EJECUTIVA $\times$ MAYORÍA $\times$ ei $\times$ acuerdo \\
\hline 6 & partidaria $\times$ EJECUTIVA $\times$ MAYORÍA $\times$ EI $\times$ acuerdo \\
\hline 7 & partidaria $\times$ EJECUTIVA $\times$ MAYORÍA $\times$ ei $\times$ ACUERDO \\
\hline 8 & PARTIDARIA $\times$ EJECUTIVA $\times$ MAYORÍA $\times$ EI $\times$ acuerdo \\
\hline 9 & partidaria $\times$ ejecutiva $\times$ MAYORÍA $\times \mathrm{EI} \times$ acuerdo \\
\hline 12 & PARTIDARIA $\times$ ejecutiva $\times$ mayoría $\times$ EI $\times$ ACUERDO \\
\hline 13 & PARTIDARIA $\times$ EJECUTIVA $\times$ mayoría $\times$ EI $\times$ ACUERDO \\
\hline 15 & partidaria $\times$ ejecutiva $\times$ MAYORÍA $\times$ ei $\times$ ACUERDO \\
\hline
\end{tabular}

NOTA: el signo de multiplicación (x) indica combinación de condiciones (Ragin 2007)

Se explica brevemente este procedimiento con un ejemplo. Las filas 5 y 8 de la tabla de verdad (Tabla 2) difieren únicamente en la variable "estrategia institucional." En consecuencia se eliminó la variable "EI" para establecer el patrón causal que 
surge al combinar las filas 5 y 8 . El Panel B muestra el resultado obtenido al simplificar los términos (Ragin 2007:203-210). Las filas 5 y 8 se muestran combinadas sin la variable "EI/ei", en un patrón causal identificado con el número 16. Este patrón causal puede resumirse del siguiente modo: el cambio político del STJ ocurrió cuando se combinó la alternancia partidaria y un nuevo gobernador dispuso de la mayoría necesaria para designar jueces del STJ. Este procedimiento de simplificación se aplicó a todas las configuraciones descriptas en la tabla de verdad (Tabla 2) hasta donde fue posible siguiendo las pautas de Ragin (2007:203-210).

Panel B. Casos de cambio político del STJ

\begin{tabular}{lll}
\hline Filas & \multicolumn{1}{c}{ Patrones causales } & Nueva denominación \\
\hline $5+8$ & PARTIDARIA $\times$ EJECUTIVA $\times$ MAYORÍA $\times$ acuerdo & ${ }^{*} 16$ \\
$6+9$ & partidaria $\times$ MAYORÍA $\times$ EI $\times$ acuerdo & ${ }^{*} 17$ \\
$7+15$ & partidaria $\times$ MAYORÍA $\times$ ei $\times$ ACUERDO & ${ }^{*} 18$ \\
$12+13$ & PARTIDARIA $\times$ mayoría $\times$ EI $\times$ ACUERDO & ${ }^{*} 19$ \\
\hline
\end{tabular}

El Panel B agrupa los cuatro patrones causales identificados que conducen al resultado de cambio político del STJ. Sin embargo, antes de pasar al análisis de los patrones del Panel B se realizó un último procedimiento para verificar si existían términos superfluos, innecesarios para describir las combinaciones causales que producen un determinado resultado. Aquí se siguió el método sugerido por Ragin (2007:208) y se construyó una tabla que indique la correspondencia entre las filas del Panel A y los términos simplificados del Panel B. La Tabla 3 revela que no existen términos redundantes que eliminar.

El primer patrón ${ }^{*} 16$ en el Panel B) revela casos en que hubo alternancia partidaria y llegó un nuevo gobernador que reunió la mayoría necesaria para designar jueces del STJ y produjo un cambio político del STJ por vía de Imposición (sin necesidad de cooptación ni negociación).

El segundo patrón $\left({ }^{*} 17\right)$ puede expresarse del siguiente modo: hubo cambio político del STJ en casos en que no hubo alternancia partidaria pero el gobernador tenía mayoría y desplegó alguna de las estrategias institucionales señaladas por Castagnola (2010a, 2012), sin necesidad de cooptación ni negociación. La estrategia institucional permitió a los gobernadores de estos casos obtener vacantes para cubrir en el STJ, y como tenían mayoría pudieron designar jueces por Imposición.

El tercer patrón $\left({ }^{*} 18\right)$ abarca casos en que el cambio político del STJ se produjo sin alternancia partidaria, pero con un gobernador cuyo partido reunía la mayoría para designar un juez del STJ y realizó un acuerdo político. En este patrón se ubican casos en los que los gobernadores recurrieron a mecanismos de cooptación o de negociación para concretar un cambio político en el STJ. Antes que utilizar una estrategia institucional, recurrieron a la arena legislativa. 
El cuarto patrón $\left({ }^{*} 19\right)$ deriva de casos en que hubo alternancia partidaria pero el gobernador no reunía la mayoría para designar jueces del STJ, y sin embargo a través de estrategias institucionales y de un acuerdo político (cooptación o negociación) produjo un cambio político del STJ. Los casos concretos de este patrón son dos y evidencian los mecanismos de negociación (Chubut 20032007) y de cooptación (Misiones 2003-2007). La particularidad de ambos casos es que al momento del cambio político en el STJ exigían un umbral alto para designar un juez del STJ (dos tercios de la legislatura), una mayoría que pocas provincias exigen para el nombramiento de un juez de la Corte.

Tabla 3. Representatividad de los términos simplificados

\begin{tabular}{|c|c|c|c|c|}
\hline \multirow[b]{2}{*}{ Filas de la tabla de verdad* } & \multicolumn{4}{|c|}{ Términos simplificados* } \\
\hline & $\begin{array}{c}\text { PARTIDARIA } \\
\times \text { EJECUTIVA } \\
\times \text { MAYORÍA } \times \\
\text { acuerdo }\end{array}$ & $\begin{array}{c}\text { partidaria } \times \\
\text { MAYORÍA } \\
\times \text { EI } \times \\
\text { acuerdo }\end{array}$ & $\begin{array}{c}\text { partidaria } \times \\
\text { MAYORÍA } \\
\times \text { ei } \times \\
\text { ACUERDO }\end{array}$ & $\begin{array}{c}\text { PARTIDARIA } \\
\times \text { mayoría } \\
\times \text { EI } \times \\
\text { ACUERDO }\end{array}$ \\
\hline $\begin{array}{l}\text { PARTIDARIA } \times \text { EJECUTIVA } \\
\times \text { MAYORÍA } \times \text { ei } \times \text { acuerdo }\end{array}$ & $x$ & & & \\
\hline $\begin{array}{l}\text { partidaria } \times \text { EJECUTIVA } \times \\
\text { MAYORÍA } \times \text { EI } \times \text { acuerdo }\end{array}$ & & $x$ & & \\
\hline $\begin{array}{l}\text { partidaria } \times \text { EJECUTIVA } \times \\
\text { MAYORÍA } \times \text { ei } \times \text { ACUERDO }\end{array}$ & & & $x$ & \\
\hline $\begin{array}{l}\text { PARTIDARIA } \times \text { EJECUTIVA } \\
\times \text { MAYORÍA } \times \text { EI } \times \text { acuerdo }\end{array}$ & $x$ & & & \\
\hline $\begin{array}{l}\text { partidaria } \times \text { ejecutiva } \times \\
\text { MAYORÍA } \times \text { EI } \times \text { acuerdo }\end{array}$ & & $x$ & & \\
\hline $\begin{array}{l}\text { PARTIDARIA } \times \text { ejecutiva } \times \\
\text { mayoría } \times \text { EI } \times \text { ACUERDO }\end{array}$ & & & & $x$ \\
\hline $\begin{array}{l}\text { PARTIDARIA } \times \text { EJECUTIVA } \\
\times \text { mayoría } \times \text { EI } \times \text { ACUERDO }\end{array}$ & & & & $x$ \\
\hline $\begin{array}{l}\text { partidaria } \times \text { ejecutiva } \times \\
\text { MAYORÍA } \times \text { ei } \times \text { ACUERDO }\end{array}$ & & & $x$ & \\
\hline
\end{tabular}

Nota: *Las filas de la tabla de verdad provienen del Panel A. Los términos simplificados provienen del Panel B.

\section{ANÁLISIS DE CASOS POR MECANISMO}

En esta sección se discuten muy brevemente algunos casos relevados en la tabla de verdad, agrupados en función del mecanismo correspondiente.

\section{Imposición: Mendoza 1983-1987}

En 1983 la UCR alcanzó el 50 por ciento de las bancas del Senado mendocino, y el 60 luego de las elecciones de 1985. En ese contexto, el gobernador Santiago 
Llaver (UCR, 1983-1987) pudo imponer a los jueces de su preferencia en la Corte sin necesidad de negociar con otros partidos o facciones partidarias. Todos los jueces designados en ese período ejercían cargos políticos en representación de la UCR o tenían vínculos cercanos con el radicalismo gobernante (Bill Chavez 2004:85-133). Antes de finalizar su mandato, Llaver logró cambiar a cuatro de los siete jueces de la Corte mendocina, ${ }^{14}$ y lo hizo apenas un par de semanas antes de que asumiera la gobernación el candidato electo del peronismo José Octavio Bordón (gobernador entre 1987-1991).

\section{Negociación: Chubut 2003-2007}

En 2003 el nuevo gobernador Mario Das Neves (PJ) se encontró con un STJ de tres jueces, dos de los cuales habían sido designados por la UCR. La reforma constitucional realizada entre UCR y PJ (Micozzi 2001) elevó la mayoría legislativa a 2/3 para designar jueces del STJ.

En 2006 el entonces gobernador Mario Das Neves promovió un proyecto en la legislatura de Chubut para ampliar la composición del STJ de tres a seis miembros (máximo previsto en la Constitución local) a partir de la creación de la Sala Penal. Al mismo tiempo envió los pliegos de tres candidatos para cubrir esos nuevos cargos. El partido del gobernador Das Neves (PJ) no reunía los dos tercios necesarios, pero la negociación de un acuerdo con seis legisladores radicales que respondían al exgobernador José Luis Lizurume (UCR) les permitió a los legisladores del PJ contar con la mayoría necesaria de dos tercios. El cambio político de jueces del STJ llegó a partir de la negociación.

\section{Cooptación: Misiones 2003-2007}

Entre fines de 2005 y la primera mitad de 2006, el Frente Renovador (FR) consiguió modificar la composición del STJ misionero y designó a cuatro nuevos jueces en la Corte local. Para efectuar esos nombramientos no contaba con mayoría de dos tercios en la legislatura. Sin embargo, el gobernador logró cooptar a tres legisladores individuales (dos del PJ y uno de la UCR) y de ese modo reunió la mayoría necesaria para presionar la salida de jueces del STJ y designar reemplazantes. Sólo consiguió cooptar legisladores individuales de otras facciones partidarias después de haber ganado las elecciones legislativas de 2005, ya que entre 2003 y 2005 el PJ y la UCR disponían de un interbloque legislativo mayoritario en oposición al FR.

14 El gobernador radical Llaver propuso a cuatro candidatos para el STJ pero el Senado provincial rechazó a uno. Sin embargo, el gobernador envió un reemplazo y pudo concretar el cambio político en el STJ, con lo cual se codificó como Imposición. 


\section{Bloqueo: Ciudad de Buenos Aires 2007-2011}

En 2009 se jubiló un integrante del STJ que ejercía la presidencia del máximo órgano judicial. En poco tiempo el entonces Jefe de Gobierno Mauricio Macri (PRO) envió a la legislatura el pliego de una candidata para integrar la Corte. Sin embargo, las objeciones a la candidatura, surgidas en la legislatura, motivaron un prolongado proceso de conflicto político, no exento de fallos judiciales, y un intento del oficialismo de plantear un conflicto de poderes. Se realizó una audiencia pública el 30/10/2009 que sólo dejó al descubierto las objeciones a la candidata del oficialismo, y la ausencia de la mayoría legislativa necesaria para promover la designación. Finalmente, la candidata renunció a la postulación (Diario Página 12, 9/9/2010) luego de casi un año de la celebración de la audiencia pública. El bloqueo de la postulación pretendida por el Jefe de Gobierno dejó abierta la vacante en el STJ porteño en ese momento. ${ }^{15}$

\section{VII.CONCLUSIONES}

A partir de este trabajo se discuten brevemente cinco temas relevantes. En primer lugar, los resultados del análisis comparativo muestran que los gobernadores pudieron superar la falta de mayoría legislativa a través de los mecanismos de negociación y de cooptación. El análisis de los patrones causales de los casos en que hubo cambios políticos del STJ mostró que, aunque no tengan la mayoría necesaria para designar o destituir jueces de los STJ, los gobernadores pueden superar esa fragmentación negociando acuerdos con otros partidos o facciones partidarias, o bien cooptando a algunos legisladores individuales. La ausencia de una mayoría para designar jueces de la Corte no impidió a los gobernadores realizar un cambio político del STJ. Este resultado coincide con el hallazgo de Leiras, Giraudy y Tuñón (2015), quienes desde otra perspectiva señalan que la fragmentación legislativa no siempre impide cambios en los STJ. Este hallazgo destaca la necesidad de analizar qué ocurre en la arena legislativa y las estrategias que despliegan los gobernadores para superar la falta de mayoría de su propio partido. Los mecanismos de negociación y cooptación propuestos en este trabajo constituyen un aporte en ese sentido para la literatura de estudios judiciales comparados.

En segundo lugar, los resultados de la tabla de verdad revelan los alcances de la propuesta teórica presentada porque en tres provincias se encontraron casos de jueces del STJ que renunciaron sin la amenaza de destitución. ${ }^{16}$ Existen casos en los cuales los gobernadores obtuvieron las renuncias de jueces del STJ sin contar con la amenaza de destitución, y sin que fuera posible determinar la existencia de cooptación o negociación para forzar las renuncias. Si

15 Recién en el año 2013 se cubrió la vacante del STJ porteño, esta vez sí con el suficiente respaldo legislativo negociado (Diario de Sesión, 30/5/2013).

16 Entre Ríos 1991-1995, La Pampa 1991-1995 y San Luis entre 1991-1999. 
bien sería necesario profundizar la investigación, este resultado sugiere que efectivamente en algunos casos los jueces del STJ renunciaron ante presiones informales, como sostiene Castagnola (2010a, 2012), sin que los gobernadores tuvieran la amenaza de destitución. Esto coloca en primer plano los posibles motivos personales de los jueces para renunciar ante presiones informales en contextos en que no enfrentan una real amenaza de juicio político. Los ejemplos más reiterados se encuentran en la provincia de Entre Ríos, donde en sucesivas ocasiones hubo renuncias de varios jueces del STJ a partir del ofrecimiento de jubilaciones especiales, sin una amenaza concreta de juicio político.

En tercer lugar, si bien la tabla de verdad no permitió realizar una detección sistemática de casos de bloqueo, la evidencia recogida al elaborar la tabla de datos demostró que es necesario un estudio más profundo para conocer mejor las situaciones de bloqueo a iniciativas de los gobernadores, aun cuando el partido del gobernador dispone de mayoría. Futuros trabajos podrían informarnos más sobre casos de bloqueo que podrían ser más frecuentes de lo que sugiere la literatura de estudios judiciales comparados (Castagnola 2010a, 2012; Leiras, Giraudy y Tuñón 2015). Los casos del gobernador Binner (PS, 2007-2011) en Santa Fe y de Capitanich (PJ, 2007-2011) en Chaco, que cuestionaron a los jueces de sus Cortes provinciales sin poder cambiarlos, son ejemplos del mecanismo del Bloqueo. ${ }^{17}$ Puede objetarse que se trata de casos aislados que no muestran un patrón. Pero aun aceptando que se tratara de casos aislados, su existencia obliga a no dar por supuesto aquello que merece ser objeto de investigación más profunda: que los gobernadores no siempre pueden imponer lo que buscan.

En cuarto lugar, este trabajo no incluyó una variable de legitimidad de los jueces de las Cortes provinciales por la ausencia de datos, pero de alguna manera debe ser considerada en trabajos futuros. La legitimidad de los jueces del STJ ante la opinión pública aporta información relevante (Walker 2017), porque puede afectar no sólo la decisión de los gobernadores de realizar un cambio político en el STJ sino también la disposición de los legisladores a apoyar iniciativas que modifiquen la composición de la Corte. Por ejemplo, para entender cuándo y por qué los gobernadores eligen realizar cambios políticos en el STJ a través de la ampliación del tamaño de la Corte, y cuándo se inclinan por impulsar juicios políticos para destituir jueces del STJ como paso previo a nuevos nombramientos.

Por último, un comentario con relación a la cantidad de provincias argentinas estudiadas (10 sobre 24). Como se planteó más arriba, la tabla de verdad se

$17 \quad$ Hermes Binner (partido socialista) llegó a la gobernación de Santa Fe 2007, y Jorge Capitanich (PJ) a la gobernación de Chaco en 2007 por primera vez. Ambos casos son ejemplos de gobernadores que se encontraron con Cortes de justicia integradas por miembros con clara afiliación partidaria con partidos de oposición (del peronismo en el caso de Santa Fe y del radicalismo en el caso de Chaco). Ambos gobernadores cuestionaron en duros términos a los jueces de sus respectivas Cortes, pero sin embargo no lograron que los jueces renuncien a sus cargos. Y el partido de ambos gobernadores no reunía suficiente respaldo legislativo como para amenazar con juicio político a los jueces del STJ. 
elaboró con diez provincias por falta de información. Ante la dificultad para obtener información completa, fundamentalmente el listado exhaustivo de jueces que integraron los STJ entre 1983-2011, se priorizó reconstruir información de provincias que fueran lo suficientemente diversas entre sí respecto de las variables clave. El poder partidario de los gobernadores, la presencia y ausencia de alternancia partidaria y ejecutiva, un diseño institucional diferente para designar jueces de las Cortes, y mayorías más laxas o más restrictivas para esas designaciones, son algunos de los ejes con los cuales se buscó reconstruir una muestra diversa de provincias argentinas. ${ }^{18}$ Dadas las dificultades para obtener información completa de todas, con esta estrategia se buscó asegurar que la tabla reuniera provincias diversas en variables clave para tener una muestra representativa de la mayoría de las provincias. Con esta estrategia se logró incluir casos extremos como San Luis, donde gracias a la reelección indefinida un mismo gobernador estuvo al frente del poder provincial durante cinco mandatos, junto a casos donde no se permitía la reelección inmediata y por ende cambiaba el gobernador cada cuatro años (Mendoza, Santa Fe y Entre Ríos). ${ }^{19}$ Entre ambos extremos, hubo casos provinciales con alternancia partidaria y con alternancia ejecutiva. Lo mismo vale para otras variables relevantes del análisis como el diseño institucional, ya que algunas provincias son unicamerales y otras bicamerales, y también hay diferencias entre las bicamerales (como muestra el Cuadro 2 de la tercera sección, en Mendoza y Entre Ríos interviene el Senado provincial en el nombramiento de jueces del STJ, mientras en Santa Fe interviene la Asamblea Legislativa).

En síntesis, esta estrategia permite fortalecer la validez de los patrones detectados con la tabla de verdad, dada la diversidad de los casos involucrados. Sin embargo, futuros trabajos podrían explorar si es posible detectar patrones idénticos en provincias más similares entre sí respecto a las variables clave. Ello requeriría reunir información completa en provincias similares, en lugar de priorizar la diversidad como se hizo aquí.

\section{REFERENCIAS}

Abdulhadi, Augusto. 2016. "Disputas faccionales y cortes judiciales en las provincias argentinas: Misiones bajo el Frente Renovador (2003-2011)." Revista SAAP 10(2): 355-374.

Atlas Electoral de Andy Tow. Recuperado el 3 de marzo de 2019 de https: / www.andytow. com/atlas/totalpais/

Basabe Serrano, Santiago. 2008. "Las preferencias ideológicas y políticas judiciales: un modelo actitudinal sobre el voto en el Tribunal Constitucional de Ecuador." América Latina Hoy 49(0): 157-177.

Behrend, Jacqueline y Laurence Whitehead. 2017. "Prácticas iliberales y antidemocráticas a nivel subnacional". Colombia Internacional (91): 17-43.

18 La forma de remoción de jueces de las Cortes, y las mayorías exigidas para ello no variaban en 22 de las 24 provincias, por lo que no servían para obtener una muestra diversa. 
Behrend, Jacqueline. 2011. "The Unevenness of Democracy at the Subnational Level. Provincial Closed Games in Argentina." Latin American Research Review 46(1): 150-176.

Bill Chavez, Rebecca. 2004. The Rule of Law in Nascent Democracies: Judicial Politics in Argentina. Stanford: Stanford University Press.

Boucek, Francoise. 2009. “Rethinking Factionalism. Typologies, Intra-Party Dynamics and Three Faces of Factionalism." Party Politics 15(4): 1-31.

Castagnola, Andrea. 2008. “¿Cómo evolucionan nuestras instituciones? Un estudio comparado de la normativa de las Cortes Supremas provinciales y de la Corte Suprema de Justicia de la Nación desde 1984 hasta 2008". Asociación por los Derechos Civiles (ADC).

Castagnola, Andrea. 2010a. "Rethinking Judicial Instability in Developing Democracies: A National and Subnational Analysis of Supreme Courts in Argentina." Tesis Doctoral. University of Pittsburgh.

Castagnola, Andrea. 2010b. "La diversidad institucional de los poderes judiciales provinciales en Argentina desde una perspectiva histórica." Revista POST-Data 15(2): 161-189.

Castagnola, Andrea. 2012. "I Want it All, and I Want it Now: the Political Manipulation of Argentina's Provincial High Courts." Journal of Politics in Latin America 4(2): 39-62.

Diario de Sesión de la Legislatura de la Ciudad de Buenos Aires, 30/5/2013.

Diario Norte, Chaco, 30/4/1993.

Diario El Pregón, Jujuy, 6/8/2004, 11 y 12/11/2004, 20/9/2005, 29/12/2007.

Diario Página 12, Ciudad de Buenos Aires, 9/9/2010.

Gervasoni, Carlos. 2010. "A Rentier Theory of Subnational Regimes. Fiscal Federalism, Democracy, and Authoritarianism in the Argentine Provinces." World Politics 62(2): 302340.

Helmke, Gretchen. 2002. "The Logic of Strategic Defection: Court-Executive Relations in Argentina under Dictatorship and Democracy." American Political Science Review 96(2): 291-303.

Hilbink, Lisa. 2007. Judges beyond Politics in Democracy and Dictatorship: Lessons from Chile. New York: Cambridge University Press.

Iaryczower, Matías, Pablo Spiller y Mariano Tommasi. 2002. “Judicial Independence in Unstable Environments. Argentina 1935-1998." American Journal of Political Science 46(4):699-716.

Ingram, Matthew. 2012. "Crafting Courts in New Democracies: Ideology and Judicial Council Reforms in Three Mexican States." Comparative Politics 44 (4): 439-458.

Lara Borges, Oswald, Andrea Castagnola y Aníbal Pérez Liñán. 2012. “Diseño constitucional y estabilidad judicial en América Latina, 1900-2009." Política y Gobierno 19(1): 3-40.

Leiras, Marcelo, Agustina Giraudy y Guadalupe Tuñón. 2015. “Who Wants an Independent Court? Political Competition and Supreme Court Autonomy in the Argentine Provinces (1984-2008)." Journal of Politics 77(1): 175-187.

Leiras, Marcelo. 2007. Todos los caballos del rey. La integración de los partidos políticos y el gobierno democrático de la Argentina, 1995-2003. Buenos Aires: Prometeo-PENT.

Llanos, Mariana, Cordula Tibi Weber, Charlotte Heyl y Alexander Stroh. 2016. "Informal Interference in the Judiciary in New Democracies: a Comparison of six African and Latin American Cases." Democratization 23(7): 1236-1253.

Micozzi, Juan Pablo. 2001. "Reformas institucionales en Chaco, Chubut y La Pampa. Tres procesos convergentes, ¿tres procesos idénticos?." Ponencia presentada en el V Congreso Nacional de Ciencia Política de la Sociedad Argentina de Análisis Político, Río Cuarto, 14-17 de noviembre.

O'Donnell, Guillermo. 2004. "The Quality of Democracy: Why the Rule of Law Matters." Journal of Democracy 15(4): 32-46.

Pérez Liñán, Aníbal y Andrea Castagnola. 2009. "Presidential Control of High Courts in Latin America: a Long Term View (1904-2006)." Journal of Politics in Latin America 1(2): 87-114.

Ragin, Charles. 2007. La construcción de la investigación social. Introducción a los métodos y su diversidad. Bogotá: Siglo del Hombre Editores (SHE). 
Ríos Figueroa, Julio. 2007. “Fragmentation of Power and the Emergence of an Effective Judiciary in Mexico, 1994-2002." Latin American Politics and Society 49(1): 31-57.

Smulovitz, Catalina. 2010. "Judicialization in Argentina: Legal Culture or Opportunities and Support Structures?." En Cultures of Legality. Judicialization and Political Activism in Latin America, editado por Javier Couso, Alexandra Huneeus y Rachel Sieder. New York: Cambridge University Press.

Walker, Lee Demetrius. 2017. "Courts and Decision Making in Developing Democracies." En Routledge Handbook of Judicial Behavior, editado por Robert M. Howard y Kirk A. Randazzo. New York: Routledge.

Ward, Artemus. 2003. Deciding to Leave: The Politics of Retirement from the United States Supreme Court. Albany: State University of New York Press.

Whittington, Keith E. 2007. "Presidents, Senates, and Failed Supreme Court Nominations." The Supreme Court Review 2006(1):401-438.

Recibido: 18 de marzo de 2019

Aceptado: 16 de abril de 2020

Augusto Abdulhadi. Licenciado en Ciencia Política por la Universidad de Buenos Aires (UBA). Magíster en Desarrollo Local por la Universidad Nacional de San Martín (UNSAM). Doctor en Ciencia Política por la Universidad Nacional de San Martín (UNSAM). Docente JTP de la Escuela de Política y Gobierno (UNSAM) en "Política latinoamericana" (2009-2018) e "Introducción a la Ciencia Política" (2019). Integrante del grupo colaborador del PICT 2014-1712 "Democracia, estado y relaciones estado-sociedad en las provincias argentinas", Agencia Nacional de Promoción Científica, Fondo para la Investigación Científica y Tecnológica. Correo electrónico: aabdulhadi@unsam.edu.ar 